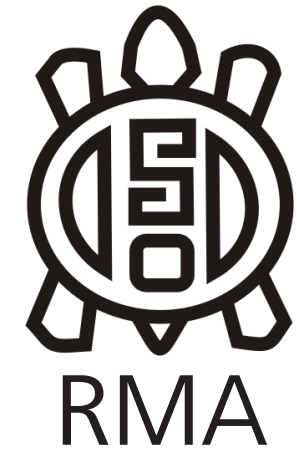

Dossier

\title{
Patrimonio arqueológico e incendios forestales. Las Yeguas, un sitio en la zona sudoccidental del lago Fagnano, Tierra del Fuego, Argentina
}

\author{
Archaeological heritage and forest fires. Las Yeguas a site in the \\ southwestern area of lake Fagnano, Tierra del Fuego, Argentina
}

María Celina Alvarez Soncini*, Vanesa Parmigiani**, Hernán De Angelis**, Anna Franch Bach**, María Estela Mansur* y Carla Pichioni***

${ }^{*}$ Centro Austral de Investigaciones Científicas (CADIC-CONICET); Calle Bernardo Houssay n² 200, Ushuaia, Tierra del Fuego, Argentina; Instituto Desarrollo Económico e Innovación, Universidad Nacional de Tierra del Fuego. E-mail: mcalvarezson@gmail.com, estelamansur@gmail.com.

${ }^{* *}$ Centro Austral de Investigaciones científicas (CADIC-CONICET), Bernardo Houssay n²00, Ushuaia, Tierra del Fuego, Argentina. E-mail: veparmigiani@yahoo.com.ar, hernandeangelis@yahoo.com.ar, anna.franch5@gmail.com.

***Universidad Nacional de Rosario (UNR), Maipu 1065 Rosario, Santa Fé, Argentina. E-mail: cali.pic.14@gmail.com.

\begin{abstract}
Resumen
El objetivo de este trabajo es presentar el resultado de las dos temporadas de campo realizadas en el sitio arqueológico Las Yeguas y el análisis de los materiales recuperados. Esto nos permitió discutir las relaciones del sitio con los recursos circundantes y la utilización del bosque como un área de ocupación por parte de las sociedades cazadoras-recolectoras que habitaron el área. Este sitio fue identificado luego de un incendio forestal que afecto intensamente la zona y que dejó expuesta gran cantidad de materiales arqueológicos. Los trabajos de campo consistieron en prospecciones y una excavación, en los cuales pudimos registrar y recuperar gran cantidad materiales arqueológicos, fundamentalmente material lítico. El análisis tecnomorfológico nos permitió una primera interpretación de los conjuntos recuperados y el nivel de alteración térmica al cual fueron expuestos. Los resultados obtenidos, si bien son preliminares, nos permiten, por un lado, ampliar el conocimiento sobre el uso de espacio en la porción occidental del lago Fagnano, y por el otro lado, reflexionar acerca de la protección del patrimonio arqueológico y la importancia de generar políticas de gestión que promuevan su cuidado.
\end{abstract}

Palabras clave: Sociedades cazadoras recolectoras; Bosque; Piedemonte; Tierra del Fuego.

\begin{abstract}
The aim of this work is to present the results of the two field seasons carried out at the Las Yeguas archaeological site and the general data of the recovered materials. This allowed us to discuss the relationships of the site with the surrounding resources and the use of the forest as an area of occupation by the hunter-gatherer societies that inhabited the area. This site was identified after a forest fire that intensely affected the area and left exposed a large amount of archaeological materials. The field work consisted of surveys and an excavation, in which we were able to record and recover a large amount of archaeological materials, mainly lithic material. The techno-morphological analysis allowed us a first interpretation of the recovered assemblages and the level of thermal alteration to which they were exposed. The results obtained, although they are preliminary, allow us, on the one hand, to broaden our knowledge about the use of space in the western portion of Lake Fagnano, and on the other hand, to reflect on the protection of archaeological heritage and the importance of generate management policies that promote their care.
\end{abstract}

Key words: Hunter gatherer societies; Forest; Foothills; Tierra del Fuego.

La ocupación humana en la faja central de la Isla Grande de Tierra del Fuego es un tema relevante para la arqueología de la región, dado que a través de ella se conectan los diferentes ecosistemas del norte y sur de la
Isla, ocupados históricamente por sociedades cazadoras recolectoras. Los estudios arqueológicos en esta zona llevan varias décadas de desarrollo, sin embargo, es a partir del año 2009 cuando se comenzaron a realizar 
investigaciones sistemáticas en la costa sur del lago Fagnano, como parte del proyecto marco Proyecto Arqueológico Corazón de la Isla, el cual busca evaluar las características de la ocupación humana en el área y su relación con la explotación de recursos bióticos y abióticos dentro del bosque subantártico (Mansur et al. 2013) y el proyecto Sociedad y Ritual: Investigaciones arqueológicas en el corazón de la isla", PICT 2006-Nº 1236, ambos dirigidos por la Dra. Mansur.

En sus inicios, estas investigaciones en la costa sur del lago Fagnano estuvieron centradas, en las porciones media y oriental, donde se prospectaron diversos sectores, se identificaron numerosos sitios arqueológicos y se registraron los recursos disponibles en cada uno (De Angelis et al. 2013; Mansur et al. 2010; Parmigiani et al. 2013). En cuanto al sector occidental del lago, su estudio fue abordado con posterioridad, dada la dificultad de acceso a esta zona, que requiere el uso de una embarcación o una travesía a pie cruzando alguno de los pasos cordilleranos, en un recorrido de varios días (Alvarez Soncini et al. 2017; Parmigiani et al. 2017). Es por este motivo que el primer trabajo de relevamiento del área, comenzó en la zona de bahía Torito $\left(54^{\circ} 35^{\prime} 42.18^{\prime \prime} \mathrm{S} 68^{\circ} 16^{\prime} 12.85^{\prime \prime} \mathrm{O}\right)$, en el año 2010. En esa ocasión el objetivo del viaje fue reconocer la zona, identificar sitios arqueológicos y planificar futuros trabajos de prospección sistemática.

Posteriormente, en enero de 2012, un incendio a gran escala afectó más de $1349 \mathrm{Ha}$, incluyendo gran parte del espacio relevado en el 2010 (Fig. 1). El mismo se inició como consecuencia de una fogata mal apagada muy próxima a la bahía Torito, en la zona de la laguna Las Yeguas. Esta área era frecuentemente transitada por senderistas nacionales y extranjeros, ya que forma parte de una senda que atraviesa la cordillera por el Paso Beban, y tiene como destino final la costa sur del lago Fagnano. La gravedad del incendio estuvo dada no solo por las condiciones climáticas del momento sino también por las condiciones topográficas, ya que se extendió a través del valle del Beban y subió a la ladera de la montaña, afectando tanto zonas de bosque como de turbal.

Los incendios forestales en Tierra del Fuego no ocurren por causas naturales, ya que la fuente más común para que se produzca un incendio de este modo son los rayos, y éstos son extremadamente raros en esta región. Por este motivo no forman parte de la dinámica natural del ecosistema fueguino ni tampoco representan un beneficio a la biodiversidad como ocurre en otras regiones del planeta (Mataix Solera1999, Pausas 2012). Los daños que provocan cuando no son controlados rápidamente, son enromes y representan una perdida tanto en términos ambientales, culturales y económicos. El impacto frente a la desaparición de la vegetación facilita procesos erosivos y la pérdida de los suelos, en los que se producen cambios físicos y químicos tanto de nutrientes como del $\mathrm{pH}$, lo que genera baja fertilidad en los meses inmediatos al paso del fuego. Esta transformación de los suelos en áreas

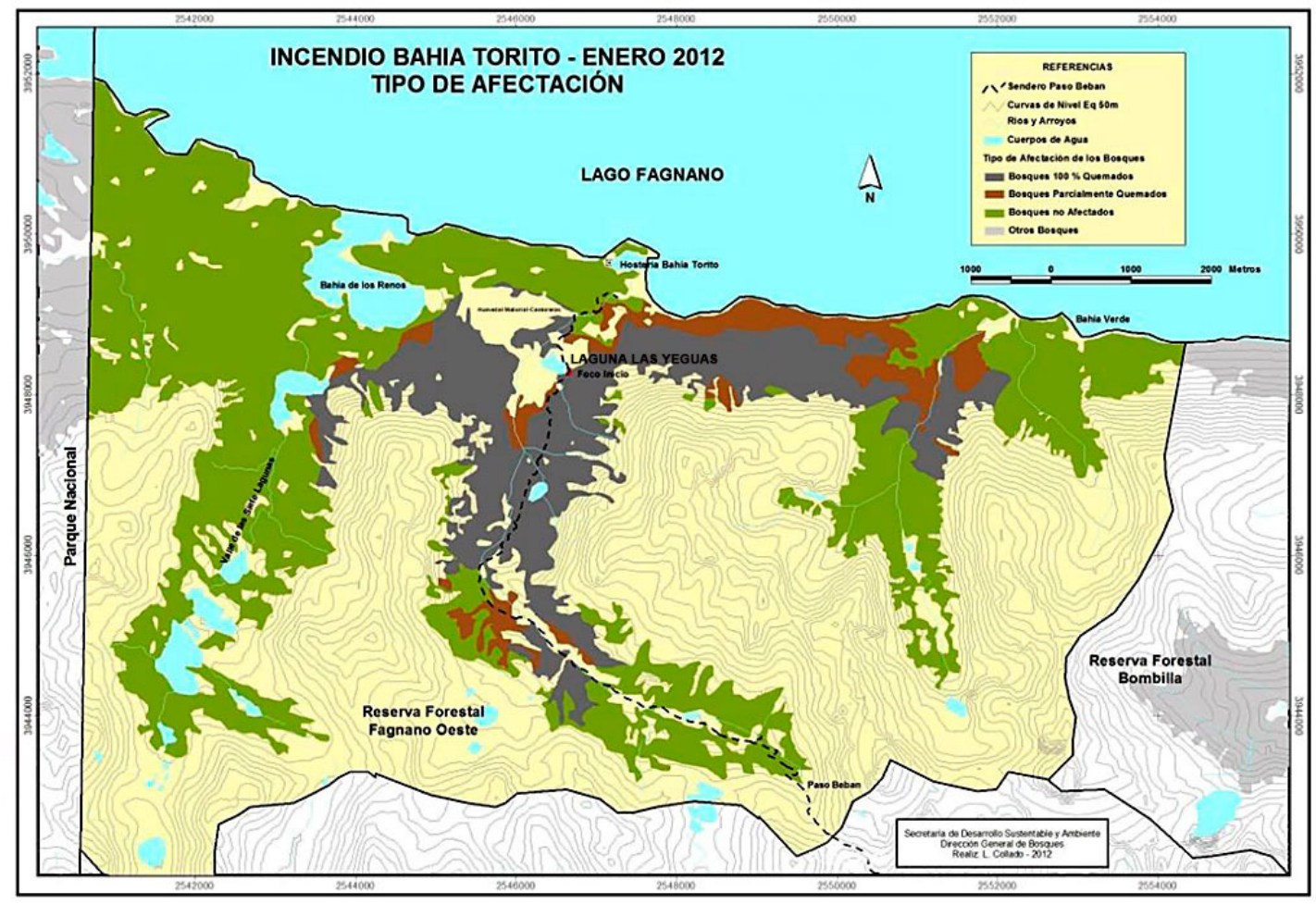

Figura 1. Área afectada por el incendio forestal en Bahía Torito (Modificado de Collado 2012).

Figure 1. Affected area by the forest fire in Bahía Torito (Modified from Collado 2012). 


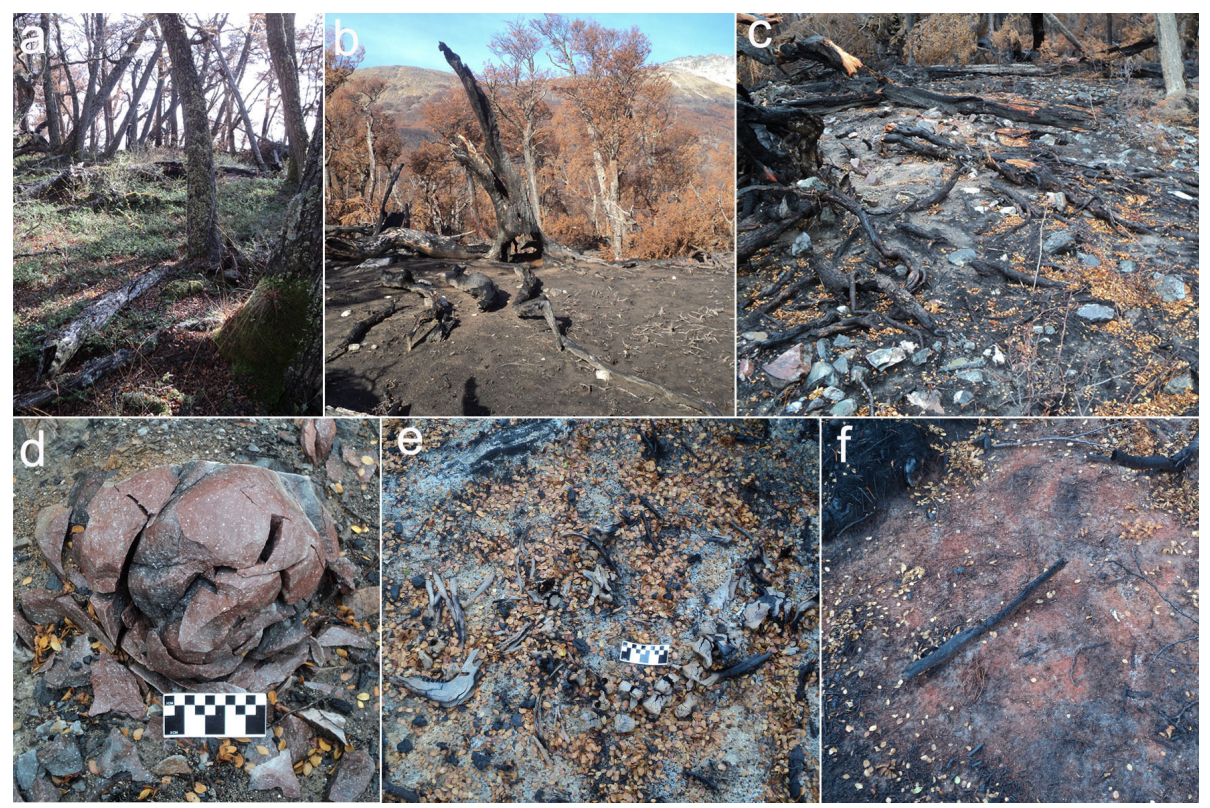

Figura 2. a) Zona de bosque no incendiada en el área de estudio. b) Zona de bosque incendiado. c) Zona de bosque incendiado con material lítico. d) Guijarros explotados por la acción del fuego. e) Fauna calcinada. f) Detalle del suelo de bosque quemado.

Figure 2. a) Non-burned forest in the study area. b) Burned forest area. c) Forest area burned with lithic material. d) Pebbles broken off fire action. e) Calcined fauna. f) Detail of the burned forest floor.

afectadas por incendios es un dato importante si tenemos en cuenta el tipo de suelo existente en el área de estudio, el cual en ciertas circunstancias puede ser propenso a la propagación de fuegos antrópicos. Asimismo, la escasa potencia que presentan y que es generalmente en la que se encuentran los materiales arqueológicos del área, es información relevante a tener en cuenta por el tipo de impacto que podría afectar a este patrimonio. Ambas características del suelo, tanto para el aspecto ambiental como para el arqueológico se describirán en profundidad más adelante.

En el caso de Bahía Torito se realizaron relevamientos posteriores al incendio que mostraron una pérdida total de especies vegetales en las zonas quemadas y la presencia de esqueletos completos calcinados de los animales que no pudieron escapar del incendio como guanacos, zorros, aves y roedores (Fig. 2), sin embargo, los muestreos para evaluar la recuperación de la vegetación en temporadas posteriores evidencian un aumento de crecimiento, que sigue los patrones normales de sucesión ecológica luego de este tipo de evento (Selzer et al. 2013). A pesar de ello, un equipo conformado por diferentes asociaciones locales está llevando adelante un proyecto de reforestación que consiste en recolección de plantas en otro sector de la costa del lago y replante en las zonas afectadas, actividad que sin duda impacta negativamente y de forma directa en los sitios arqueológicos que quedaron al descubierto como resultado de la deforestación.

Para evaluar el daño al patrimonio arqueológico producido por el incendio, realizamos una prospección en las zonas afectadas en mayo de 2012, principalmente las áreas cercanas a la costa del lago, en las cuales ya se había registrado material arqueológico con anterioridad. Sin embargo, dada la denudación del terreno ocasionada por el incendio, fue posible observar que había mayor cantidad de materiales arqueológicos en superficie (Fig. 2). La prospección se realizó desde la bahía Torito hacia el Este, siguiendo la costa del Fagnano, en un tramo de $2 \mathrm{~km}$ aproximadamente, hasta finalizar el área afectada por el fuego. Se registraron y georreferenciaron al menos 40 concentraciones de material arqueológico. El material se dejó in situ, salvo casos excepcionales.

Durante el año 2016 los trabajos de campo se orientaron a registrar el estado de los yacimientos y continuar los trabajos de prospección y relevamiento de la porción occidental del lago, donde incluimos algunos sectores al interior del bosque. En esta oportunidad relevamos la zona del incendio hacia el interior del valle en las cercanías de la laguna Las Yeguas (Fig. 3), lugar donde se había iniciado el incendio en 2010. En este sector se observó la existencia de abundante material lítico en superficie a pesar de la vegetación ya crecida, así como algunos afloramientos de rocas de buena calidad para la talla, los que potencialmente podrían haber sido utilizadas como materia prima, aunque no identificamos evidencias de extracciones. Dada la magnitud del incendio forestal nuestra hipótesis inicial en cuanto a los materiales, fue que presentarían en su mayoría un alto grado alteración producto del fuego.

El objetivo principal de este trabajo es presentar el resultado de las actividades de campo y el análisis de los materiales para discutir las relaciones de este sitio con los recursos circundantes, principalmente con el recurso lítico y la utilización del espacio de bosque como un área de ocupación y explotación por parte de las sociedades cazadoras-recolectoras de Tierra del Fuego. Asimismo, se pretende reflexionar acerca de los efectos del fuego sobre el registro arqueológico y la protección de este patrimonio. 


\section{El área de estudio}

La zona central de la Isla Grande de Tierra del Fuego se caracteriza por su particular configuración geográfica, en donde la Cordillera de los Andes actúa como eje vertebrador. El cuerpo de agua más importante corresponde al lago Fagnano (Kami), este se ubica en una depresión entre la estribación norte de la Sierra de Alvear (1300 msnm) y el flanco sur de las sierras de Beauvoir (1050 msnm) y de las Pinturas (660 msnm) (Coronato et al. 2009; Olivero et al. 1999 y 2007; Olivero y Martinioni 2001). El lago tiene $110 \mathrm{~km}$ de longitud en sentido latitudinal y alcanza un ancho máximo cercano a los $10 \mathrm{~km}$. Se alimenta por numerosos cursos de agua que descienden del sistema serrano aledaño; los mayores son los ríos Valdez y Milna por el sur, el río Turbio por el este y el río Claro por el norte. Hacia el oeste drena sobre el océano Pacífico por medio del río Azopardo, que lo conecta con el Seno Almirantazgo y el Estrecho de Magallanes. La mayor parte de los ambientes de la zona central de la isla están interconectados por valles perpendiculares al lago; esto crea corredores que hacen factible la comunicación dentro del ámbito serrano. La circulación norte-sur queda restringida al este de las cabeceras del lago Fagnano, o al oeste, a través del río Azopardo, cerca de su desembocadura (Mansur et al. 2000). Asimismo, la costa norte del Fagnano (Kami) es un corredor directo hacia los bosques orientales hasta la costa atlántica, y hacia el oeste hasta el estrecho de Magallanes (Agüero et al. 2002; Olivero et al. 2007; Martinioni 2010). Este paisaje, generado principalmente por acción glaciar, tiene gran cantidad de cuerpos de agua dulce principalmente en la zona central de la isla, como lagos, lagunas y ríos, con acumulaciones de guijarros en sus orillas, provenientes de las formaciones Lemaire, del Jurásico y Yaghán, del Cretácico, que funcionaron como fuentes secundarias de materia prima (De Angelis 2015; Mansur y De Angelis 2016; De Angelis et al. 2019; Olivero y Malumián 2008).

La vegetación de la zona sur del lago Fagnano (Kami) se caracteriza por la presencia de bosques mixtos compuestos por dos especies de Nothofagus, una perennifolia, de gran importancia desde el punto de vista de la ocupación humana debido a que brinda cobertura todo el año, Nothofagus betuloides (guindo) y otra caducifolia, Nothofagus pumilio (lenga), junto con matorrales de arbustos como Chiliotricum diffusum (mata negra), Berberis microphylla (calafate), Berberis ilicifolia (michay), Pernettya mucronata (chaura) y Empetrum rubrum (murtilla). También se documenta el desarrollo de pastizales de gramíneas y ciperáceas, en las zonas de valles y cerca de los cursos de agua (Moore 1983, Tuhkanen 1992). En este ambiente, la paludificación del suelo es muy intensiva por lo que son muy característicos los turbales con parches de Sphagnum. Los suelos han sido denominados Acid Brown ground of the Forest; en general tienen escasa potencia, están sometidos a procesos de congelamiento y descongelamiento continuos, y tienen $\mathrm{pH}$ bajo producto de la gran cantidad de hojas y materia orgánica que los cubre y que por las temperaturas bajas tarda mucho tiempo en descomponerse (Frangi et al. 2004; Moretto et al. 2005; Tuhkanen 1992). Las características de este tipo de suelo con tanta materia vegetal muerta, sumado a otros aspectos particulares de la región como los fuertes vientos o periodos con bajo nivel pluvial, pueden facilitar la propagación de los fuegos que desencadenen un potencial incendio forestal (Seltzer et al. 2013).

Los trabajos arqueológicos en la zona del Fagnano comenzaron con las investigaciones realizadas por Borrero a fines de la década de 1970, sobre la cabecera y la costa norte, en los que detectó los sitios Cabecera Fagnano 1 (CF1), interpretado como un sitio de habitación, Cabecera Fagnano 2 (CF2) y el sitio Laguna, ambos interpretados como sitios de habitación y de tareas específicas (Borrero et al. 1981). Luego, en el sector chileno, se realizaron investigaciones en la zona de bahía Inútil y la costa norte del sistema del seno Almirantazgo, el río Azopardo y el lago Fagnano, donde se registraron sitios arqueológicos superficiales con diferentes características, tamaño y densidad de materiales, ubicados tanto sobre la costa como en el interior del territorio (Ocampo y Rivas 1996).

Nuestras investigaciones en la costa sur del lago Fagnano comenzaron en 2009, en la localidad arqueológica Kami que había sido descubierta unos años antes. En Kami se estudiaron tres sitios extensos: Kami 1, Kami 6 y Kami 7. Estos sitios se caracterizan por la abundancia, riqueza y diversidad de las series líticas. Los análisis tecnofuncionales de los conjuntos líticos permitieron determinar cadenas operativas que reflejan comportamientos diferentes con respecto a la gestión de las materias primas y de los instrumentos (De Angelis 2015). Al contrario, los restos faunísticos son muy escasos debido a las malas condiciones de conservación debidas al pH del suelo que ya mencionamos anteriormente (Parmigiani 2014). En Kami 1, las dataciones radiocarbónicas de diferentes áreas de combustión dieron como resultado fechados de $3210 \pm 80$ AP (LP 2164), $1130 \pm 60$ AP (LP 2163) y $1170 \pm 60$ AP (LP 2201) (Mansur et al. 2010; De Angelis 2015). En Kami 7, los fechados dieron resultados de 1.217 \pm 38 AP (AA94284), y $178 \pm 34$ AP (AA94285); también la presencia de vidrio industrial utilizado como materia prima, lo ubica temporalmente después del siglo XVII (Parmigiani et al. 2013). El análisis espacial y la cronología permitieron corroborar que estos sitios extensos son resultado de diferentes episodios de reocupación. (De Angelis 2015; De Angelis y Mansur 2015; Mansur y De Angelis 2016).

Finalmente, la información sobre la costa sur del lago se amplió recientemente con los trabajos llevados a cabo en la porción occidental, en la zona perteneciente al Parque Nacional Tierra del Fuego (Alvarez Soncini et al. 2017; 


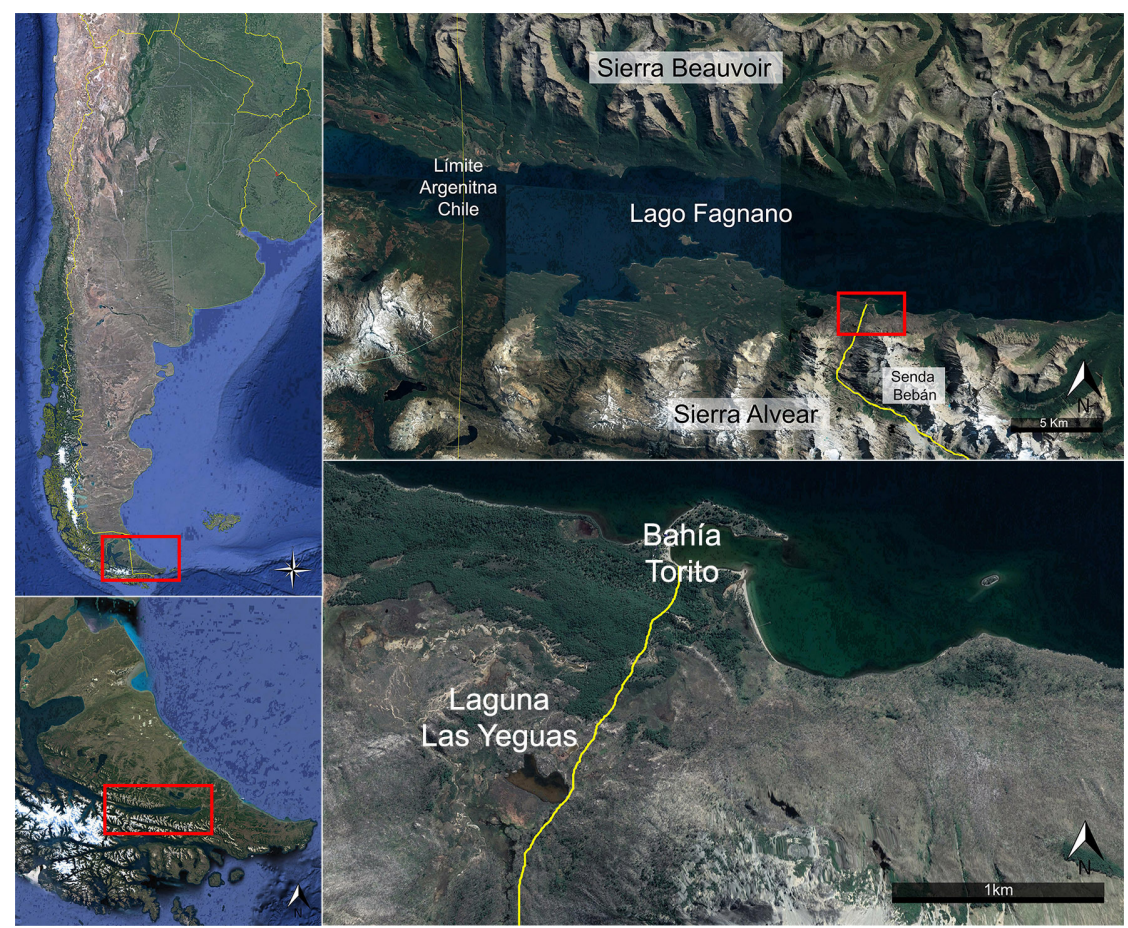

Figura 3. Mapa de la ubicación del sitio Las Yeguas.

Figure 3. Map of the location of the site Las Yeguas.

Parmigiani et al. 2017). Estos trabajos se centraron por un lado en la identificación y relevamiento de los sitios arqueológicos y por otro, en la evaluación del estado del patrimonio arqueológico. Si bien los resultados son preliminares, ratifican la existencia de numerosos sitios arqueológicos, lo que confirmaría las hipótesis sobre una alta tasa de ocupación del área en tiempos pasados.

\section{El sitio Las Yeguas}

El sitio se encuentra en las cercanías de la laguna denominada Las Yeguas, ubicada hacia el interior del

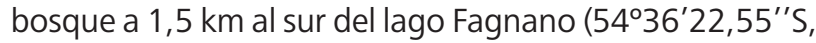
$68^{\circ} 12^{\prime} 49,39^{\prime \prime}$ ), en el tramo final de la senda conocida como Paso Beban. Una de las características más relevantes del sitio es su implantación en un área pedemontana, perteneciente a las sierras de Alvear, donde hay afloramientos riolíticos primarios con materias primas líticas de buena calidad para la talla (Fig. 3). Cabe destacar que toda la zona donde se identificaron y recuperaron los materiales arqueológicos fue afectada por el incendio forestal.

Los trabajos de campo se realizaron en dos temporadas (2016-2017). Se trabajó a partir de dos estrategias metodológicas: prospecciones sistemáticas intensivas (con registro de datos y recolección superficial del material con mayor exposición) y excavación. Para las prospecciones, se adoptó como metodología el enfoque distribucional (Dunnell y Dancey 1983; Ebert 1992; Foley 1981 a y b; Thomas 1975), que asume al registro arqueológico como una distribución continua, pero con picos en su densidad, con lo cual se considera que la variabilidad en la densidad de los artefactos arqueológicos refleja el carácter y la frecuencia de utilización del espacio (Belardi
2005; Belardi y García 1994).

Al ser muy amplia la visibilidad arqueológica, debido a la falta de cobertura vegetal luego del incendio, la capacidad de identificación de los materiales arqueológicos en superficie fue alta. Fueron identificadas y georreferenciadas 36 concentraciones que se registraron como unidades de recolección. Se recolectó la totalidad del material en 22 de ellas, en tanto que en las otras 14 se decidió dejarlas in situ ya que estaba bajo cobertura vegetal sin correr un alto riesgo de alteración (Fig. 4). Estas concentraciones se ubican en su mayoría en la margen Este y Sur de la laguna. Unos $100 \mathrm{~m}$ hacia el Norte, siguiendo un pequeño valle, hay una laguna seca en la que registramos otra serie de concentraciones. La extensión total del sitio, calculada por la presencia del material en superficie, corresponde a un área de aproximadamente $50 \mathrm{~m}^{2}$.

En cuanto a los afloramientos rocosos, estos se registraron hacia el Este de la laguna Las Yeguas, uno de ellos inmediatamente junto a las unidades de recolección. El relevamiento realizado no permitió identificar rastros de extracciones o canteo de materia prima en los afloramientos, pero cabe destacar que se mostraban algunas características de alteración térmica, como descamaciones superficiales y estallidos. Sin embargo, para tener ejemplares de estas rocas, se recolectaron algunas muestras de la materia prima identificada como riolitas de buena calidad para la talla.

Las unidades de recolección (UR) se determinaron en función de la concentración y proximidad de los materiales y del modo como se encontraban agrupados. Están compuestas exclusivamente por materiales líticos. No se 


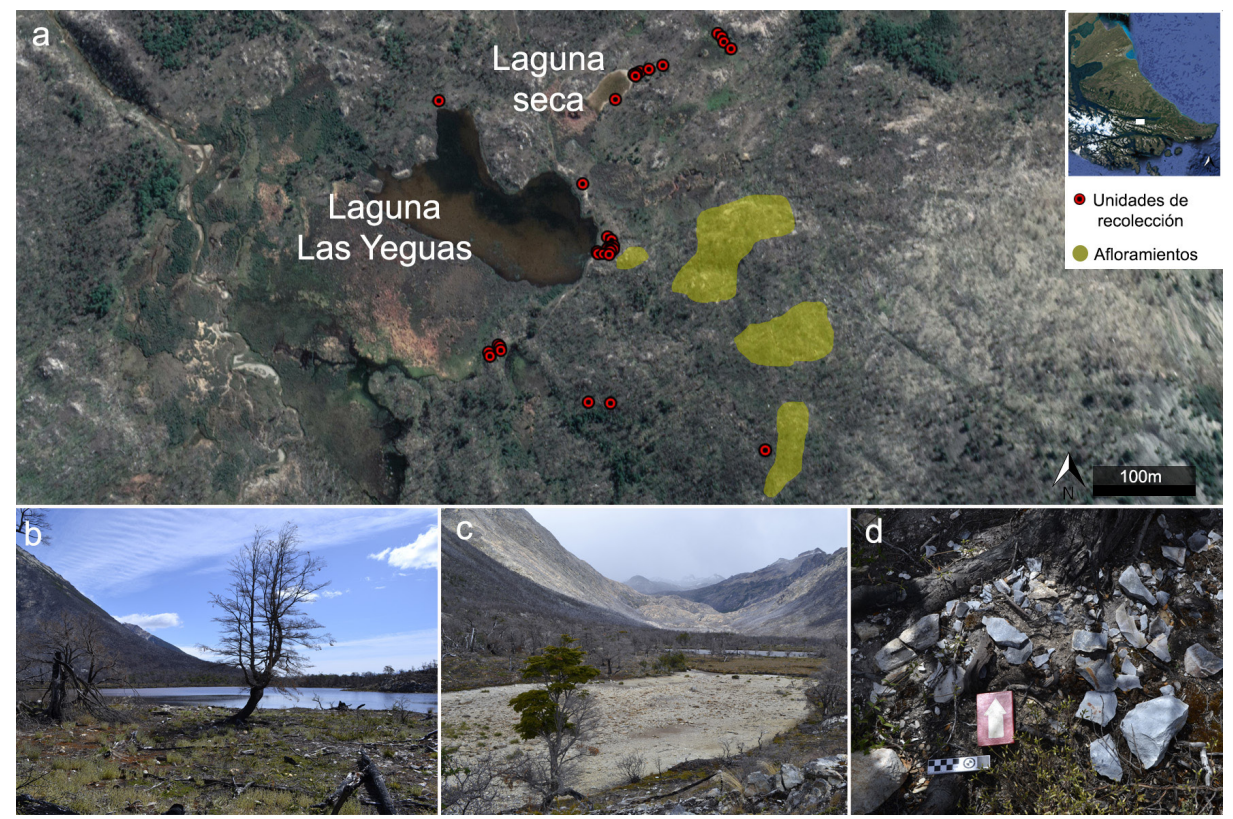

Figura 4. a) Mapa con la ubicación de las unidades de recolección y los afloramientos de materia prima. b) Laguna Las Yeguas. c) Laguna seca (al frente). Laguna Las Yeguas (detrás). El valle que lleva el paso cordillerano Beban (al fondo). d) Concentración de material lítico.

Figure 4. a) Map with the location of the collection units and the raw matrerial outcrops. b) Las Yeguas lagoon. c) Dry lagoon (in front). Las Yeguas lagoon (behind). Valley that leads the Beban mountain pass (in the background). d) Lithic material concentration.

recolectaron materiales óseos ni carbones, debido a la alta probabilidad que se tratase de materiales procedentes del incendio y no del contexto arqueológico original. En todos los casos los materiales se identificaron como conjuntos, a excepción de un único hallazgo aislado.

La excavación se llevó a cabo sobre el sector denominado unidad de recolección 17 (UR17), dado que era una de las que presentaba mayor cantidad de materiales en superficie y en la que también podíamos visualizar la continuidad del material en estratigrafía. Se ubica a unos $50 \mathrm{~m}$ al Este de la laguna $\left(54^{\circ} 36^{\prime} 23,17^{\prime \prime} \mathrm{S}, 68^{\circ} 12^{\prime} 39,47^{\prime \prime} \mathrm{O}\right)$. Al igual que las prospecciones, los trabajos de excavación se realizaron en dos temporadas. En el primer año realizamos un sondeo de $1 \mathrm{~m}^{2}$, siguiendo las capas naturales, que nos permitió definir la estratigrafía, la potencia del sitio y fundamentalmente el estado y ubicación de los materiales en función del incendio. Los resultados favorables del primer sondeo nos llevaron a ampliar la excavación en la temporada siguiente. En total se excavó una superficie de $4 \mathrm{~m}^{2}$, con cuadricula de $2 \times 2 \mathrm{~m}$, divida en sectores de $1 \mathrm{~m}^{2}$ según la posición geográfica (NO, SO, NE, SE), y a su vez estos sectores divididos en micro sectores de $0,50 \times 0,50 \mathrm{~m}$. Todos los materiales fueron recogidos por microsector (Fig. 5).

La profundidad de la excavación no supera los $15 \mathrm{~cm}$. Esta escasa potencia en la que se condensan todos los materiales arqueológicos es una característica que ya hemos observado para los otros sitios de la costa sur del lago Fagnano (De Angelis 2015, Parmigiani et al. 2013). En cuanto a la estratigrafía, esta se corresponde con el desarrollo del suelo de bosque típico del área (Frangi et al. 2004) y que fue registrada en otros sitios. Sin embargo,
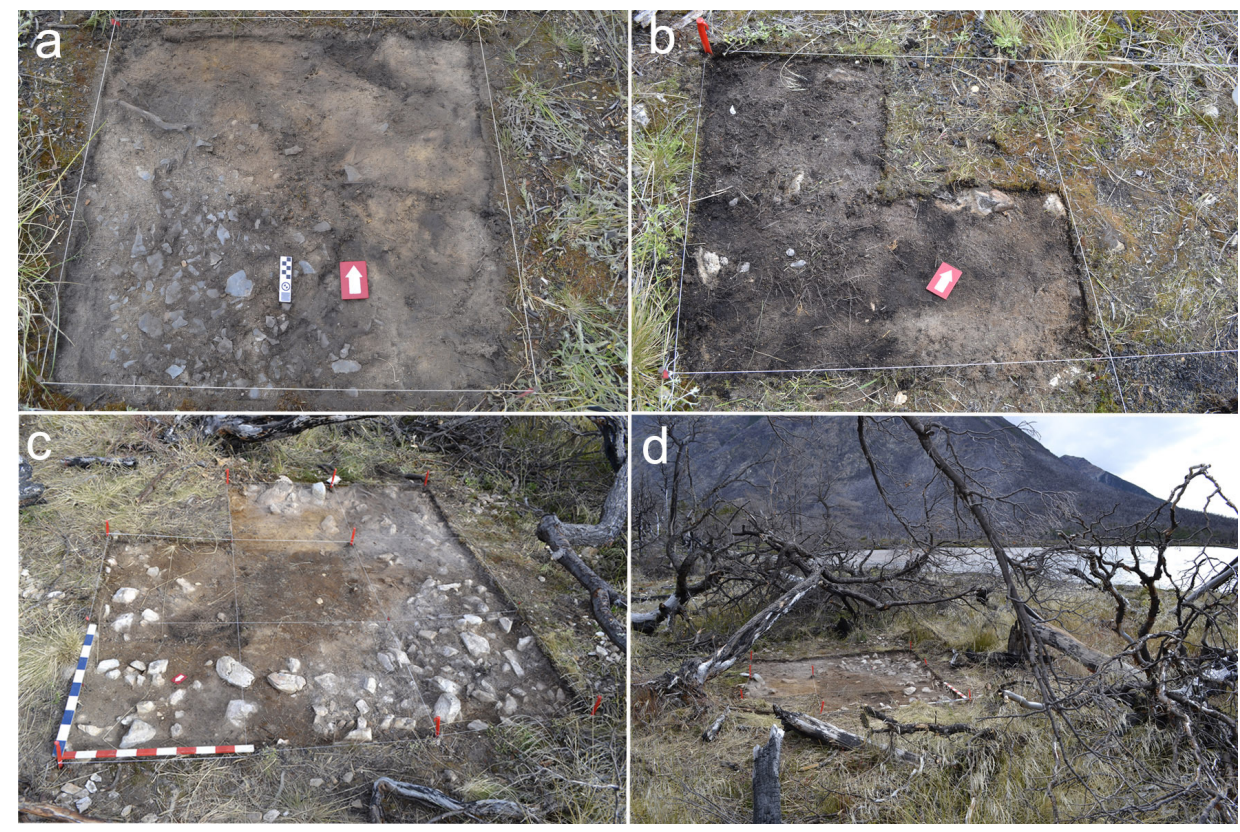

Figura 5. a) Sondeo de la primera campaña con la densidad de material lítico. b) Ampliación de la excavación con el sondeo incluido como uno de los sectores de la cuadricula. c) Planta total de la excavación, se observan los clastos del till de base. d) Ubicación de la excavación en relación con la laguna.

Figure 5. a) Archaeological survey of the first campaign with the density of lithic material. b) Extension of the excavation with the survey included as one of the sectors. c) Total excavation plant, showing the clasts of the base till. d) Location of the excavation in relation to the lagoon. 


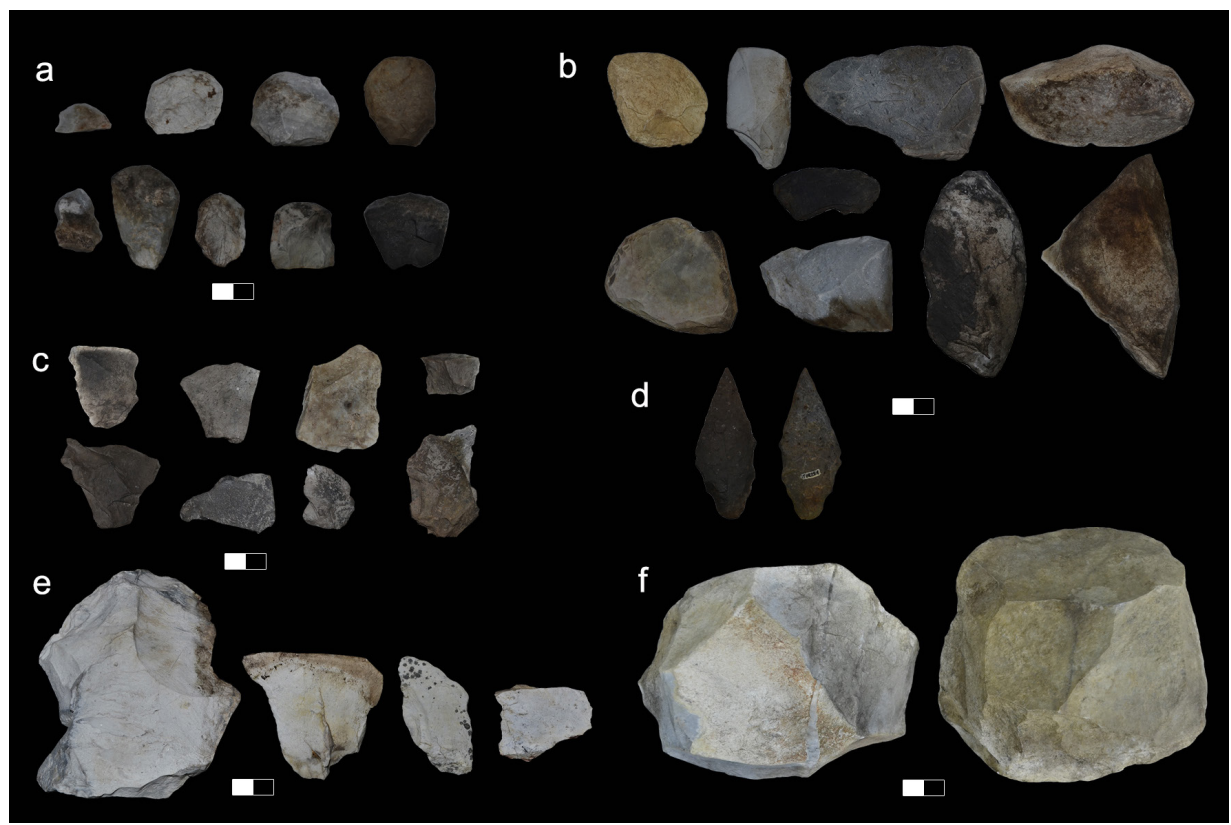

Figura 6. a) Raspadores. b) Raederas., c) Lascas y fragmentos quemados. d) Preforma de punta de proyectil. e) Lascas y fragmentos calcinados. f) Núcleos con diferente grado de alteración térmica.

Figure 6. a) Endcrapers. b) Sidescrapers. c) Burned flakes and fragments. d) Projectile point preform. e) Calcined flakes and fragments. f) Cores with different degrees of thermal alteration.

en este caso, la capa de mantillo orgánico (capa A) era delgada y estaba formada principalmente por musgo, que atribuimos al efecto del incendio (el musgo se habría formado con el paso del tiempo sobre el remanente de la capa A orgánica quemada). La siguiente capa (capa B), estaba compuesta por un sedimento marrón oscuro que en algunos sectores presentaba colores más rojizos, con una potencia entre 3 y $4 \mathrm{~cm}$. A esta le continúa la capa $C$, con un sedimento más anaranjado y de una potencia de aproximadamente $5 \mathrm{~cm}$. En estas dos capas se concentra

Tabla 1. Unidades de recolección y clasificación de los materiales líticos

Table 1. Collection units and classification for lithic materials. la mayor cantidad de material arqueológico. Finalmente, por debajo aparece el till (capa D), que en varios sectores presentaba clastos medianos y grandes.

\section{Análisis de los conjuntos líticos}

El análisis tecnomorfológico de los materiales se realizó siguiendo los criterios de clasificación propuestos por Orquera y Piana (1986-87) y Mansur y colaboradores (2000), generados en el marco del proyecto ATMA (Análisis Tecnofuncional de Materiales Arqueológicos CONICET-CADIC), que han sido adoptados para el Proyecto Arqueológico Corazón de la Isla desde sus inicios (cf. Mansur y De Angelis 2013). Estos permiten clasificar los productos de talla según su tamaño en tres categorías:

\begin{tabular}{|c|c|c|c|c|c|c|c|c|c|c|c|}
\hline & Lascas & Fragmentos & Nucleos & Raspadores & Raederas & \begin{tabular}{|c|} 
Filo \\
largo \\
retocado
\end{tabular} & $\begin{array}{l}\text { Preforma punta } \\
\text { proyectil }\end{array}$ & $\begin{array}{c}\text { Fragmento } \\
\text { retocado }\end{array}$ & Lasquitas/Debris & $\begin{array}{c}\text { Microlascas/ } \\
\text { Microfragmentos } \\
\end{array}$ & TOTAL \\
\hline UR 6 & 308 & 221 & 5 & & & & & & 558 & 5 & 1097 \\
\hline UR 12 & 149 & 121 & 3 & 2 & & & & & 443 & 13 & 731 \\
\hline UR 15 & 32 & 25 & & 1 & & & & & 42 & & 100 \\
\hline UR16 & 39 & 21 & & 1 & & & & & 15 & & 76 \\
\hline UR18 & 2 & & 1 & & & & & 1 & & & 4 \\
\hline UR2OA & 67 & 49 & 3 & & & & & 1 & 32 & & 152 \\
\hline UR2OB & 131 & 106 & & 1 & & & & & 294 & 8 & 540 \\
\hline UR2OC & 9 & 9 & & 1 & & & & & 19 & & 38 \\
\hline UR21 & 19 & 18 & 1 & & & 3 & 1 & & 16 & & 58 \\
\hline UR22 & 66 & 67 & & & & & & & 130 & & 263 \\
\hline UR23 & 94 & 75 & 2 & & 1 & & & & 69 & & 241 \\
\hline UR24 & & & 1 & & 2 & & & & & & 3 \\
\hline UR25 & 23 & 19 & 2 & & & & & & 7 & & 51 \\
\hline UR26 & & 3 & 1 & & & & & & & & 4 \\
\hline UR27 & 3 & 10 & 1 & & 1 & & & & 2 & & 17 \\
\hline UR28 & 75 & 51 & 3 & 1 & & & & & 26 & & 156 \\
\hline UR29 & 105 & 84 & 4 & & & & & & 48 & & 241 \\
\hline UR30 & 20 & 15 & 3 & & 1 & & & & 17 & & 56 \\
\hline UR31 & 5 & 7 & 1 & & 2 & & & & & & 15 \\
\hline UR32 & 4 & 4 & & & & & & & & & 8 \\
\hline UR33 & 4 & 3 & & & & & & & 3 & & 10 \\
\hline UR34 & & & & & 1 & & & & & & 1 \\
\hline TOTAL & 1155 & 908 & 31 & 7 & 8 & 3 & 1 & 2 & 1721 & 26 & 3862 \\
\hline
\end{tabular}




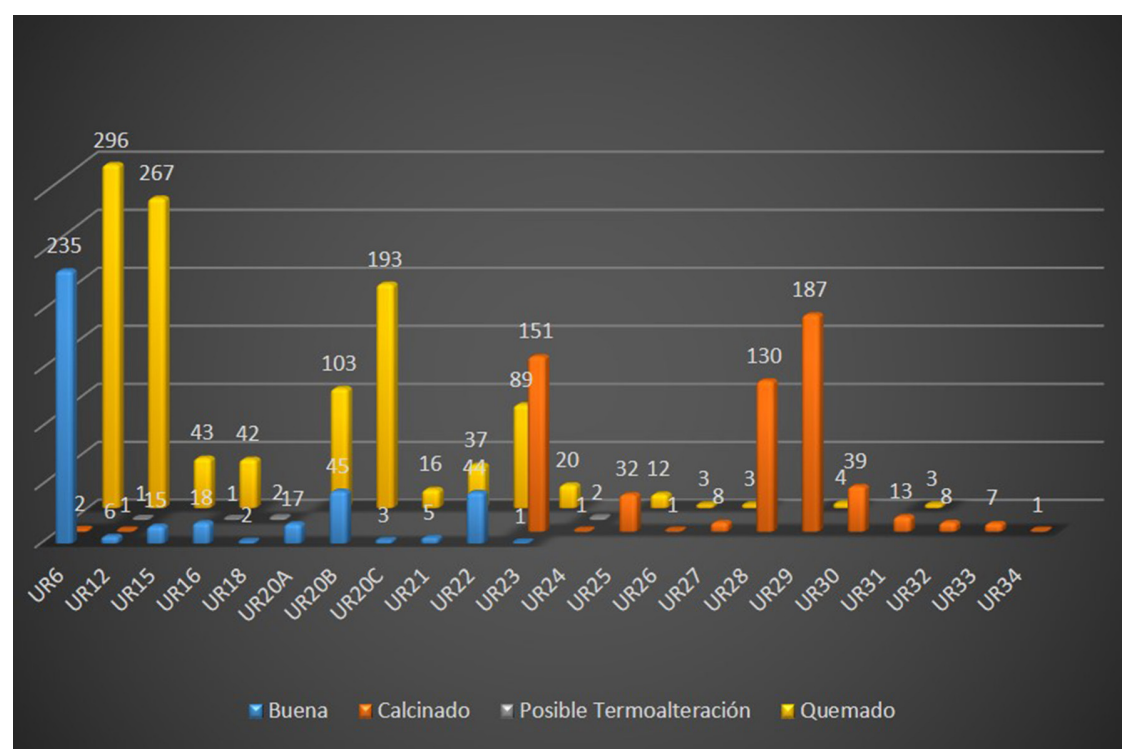

Figura 7. Alteración térmica por unidad de recolección.

Figure 7. Thermal alteration per collection unit.

lascas y fragmentos mayores de $2 \mathrm{~cm}$, lasquitas y debris entre 0,5 y $2 \mathrm{~cm}$ y microlascas y microfragmentos menores a 0,5 cm (Parmigiani et al. 2013) Esta división también se tiene en cuenta para los materiales retocados. El análisis realizado hasta el momento es inicial, sin embargo, nos permite mostrar un panorama general de las principales características.

El material lítico recuperado entre todas las unidades de recolección consta de 3862 elementos (Tabla 1), para su estudio se agruparon según la densidad artefactual: el $36 \%$ son conjuntos con menos de 20 piezas. Un $50 \%$ de los conjuntos se compone de entre 50 y 300 piezas y un $14 \%$ está compuesto por conjuntos con más de 500 piezas.

La mayoría de los elementos corresponde a restos de talla mayores a $2 \mathrm{~cm}$ (lascas y fragmentos) seguidos en número por los restos de talla menores a $2 \mathrm{~cm}$ (lasquitas y debris). El $64 \%$ de los conjuntos contienen al menos un núcleo, estos son en su mayoría de morfología discoidal. Los artefactos retocados son escasos, entre los que predominan las raederas $(n=8)$ y los raspadores $(n=7)$. Las materias primas representadas son principalmente rolitas de grano fino y medio de color gris (en los casos que no presentan alteración térmica); además se identificó un fragmento de cuarzo y un cristal de roca. Hay un porcentaje de piezas en las que no se identificó la materia prima, debido al grado de alteración producido por el fuego. La mayor parte de los materiales mayores de $2 \mathrm{~cm}$ no presentan corteza (90\%), en el $10 \%$ restante se identificó presencia de corteza escasa (3,8\%), parcial $(3,1 \%)$, abundante $(2,8 \%)$ y muy abundante $(0,3 \%)$. En cuanto a las técnicas de talla, se identificaron productos de talla por percusión directa, sin evidencias de talla bipolar (Fig. 6).

Los materiales fueron agrupados en función de la alteración térmica que presentaban, dado que a priori

Figura 8. a) Raspadores recuperados en la excavación. b) Núcleo remontado de riolita gris con vetas rojas, uno de los fragmentos presenta rastros de termoalteración.

Figure 8. a) Endscrapers recovered from the excavation. b) Refitted core of gray rhyolite with red streaks, one of the fragments shows traces of thermo-alteration.

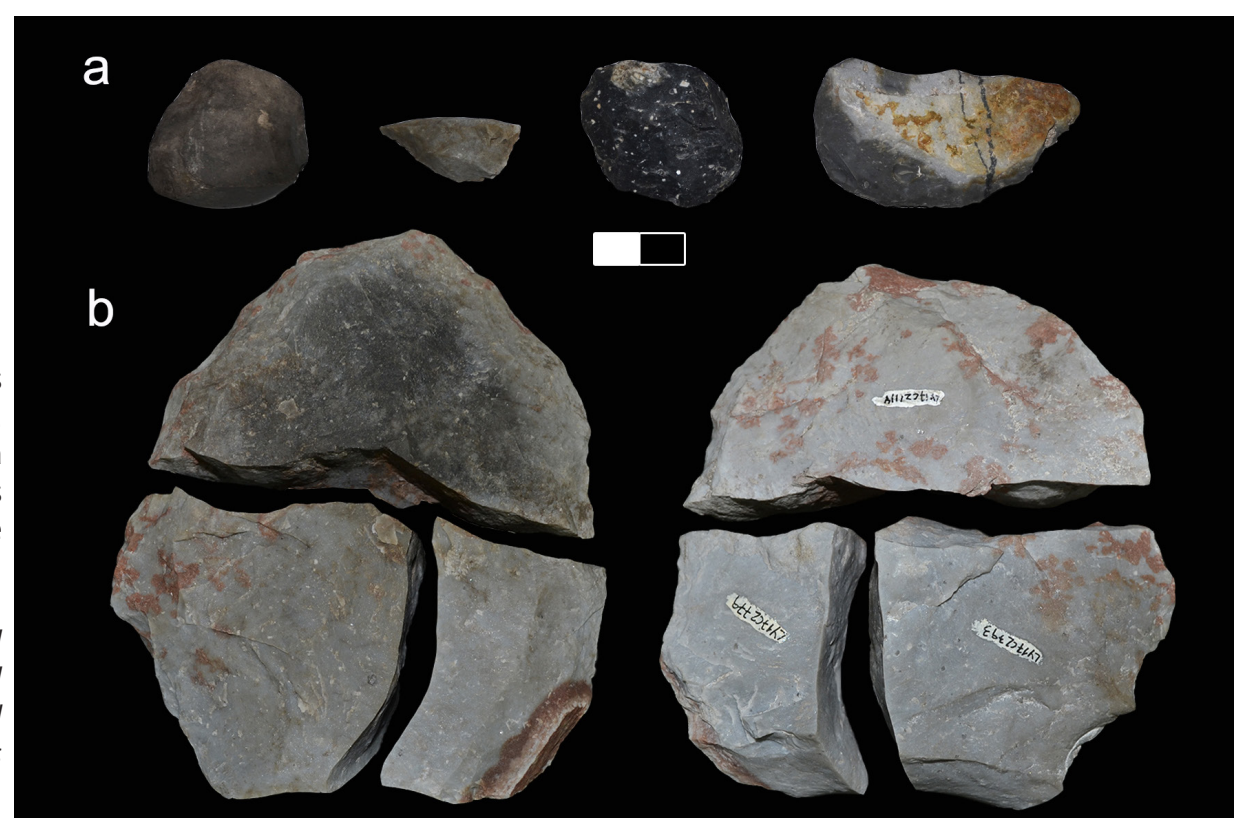

ISSN 1852-060X (impreso) / ISSN 1852-4826 (electrónico) 
se esperaba encontrar un número muy bajo de piezas sin alteración a escala macroscópica. Se clasificaron según su estado de conservación: buenos cuando no presentaban alteración a simple vista, con posible termoalteración, quemados y calcinados. Los resultados del análisis mostraron que todos los conjuntos presentan alguna de las alteraciones, siendo el quemado la más abundante (54\%), seguido del calcinado (28\%). Sin embargo, el $18 \%$ de las piezas se encuentran en buen estado de conservación, sin alteración térmica que se observe macroscópicamente (Fig. 7). El análisis microscópico de los materiales que se efectúa junto con el análisis tecnofuncional nos permitirá establecer las características de las alteraciones producidas por el fuego, que se discuten más abajo.

El material lítico procedente de la excavación consta de 4590 elementos: 1186 mayores a $2 \mathrm{~cm}$ y 3404 menores a $2 \mathrm{~cm}$. Entre los restos de talla de menos de $2 \mathrm{~cm}$ se identificaron lasquitas $(n=1138)$, debris $(n=2084)$, microlascas $(n=56)$ y microfragmentos $(n=126)$. En cuanto a los restos de talla mayores a $2 \mathrm{~cm}$, se contabilizaron 701 lascas, 474 fragmentos y 6 fragmentos de núcleos, 3 de ellos remontan entre sí, con una morfología discoidal. Los artefactos retocados constan de 4 raspadores y 1 fragmento de artefacto retocado.

La materia prima más abundante es la riolita de grano fino, principalmente de color gris, aunque en 14 piezas la rolita presenta vetas rojas naturales (Fig. 8). Se registró un porcentaje menor al $1 \%$ de materia prima no identificada. La mayor parte de los materiales no presentan corteza (84\%), en el $16 \%$ restante se identificó corteza escasa $(8 \%)$, parcial $(5 \%)$, abundante $(2 \%)$ y muy abundante (1\%). En cuanto a las técnicas de talla se evidencian productos de talla directa, como en el caso anterior tampoco se identificaron hasta el momento productos de talla bipolar. Finalmente, el estado de conservación, a nivel macroscópico de las piezas, muestra que el 90\% se encuentra en buen estado sin rastros de termoalteración, un $9 \%$ se presenta en estado quemado o con rastros de posible termoalteración y solo el $1 \%$ se identificaron como calcinados.

\section{Discusión}

Los datos obtenidos en las prospecciones y el análisis de los conjuntos líticos recuperados en la recolección superficial nos permiten discutir algunos resultados sobre las características del sitio Las Yeguas, el estado de conservación y la distribución de los materiales arqueológicos. El sitio corresponde a lo que habitualmente se clasifica como "sitio extenso", es decir aquellos formados por numerosas concentraciones de materiales arqueológicos que guardan algún tipo de continuidad entre ellas por la existencia de materiales dispersos, que permiten considerarlo como un sitio único. Frecuentemente se trata de palimpsestos horizontales producidos por la reiteración de ocupaciones en una misma área (Mansur et al. 2010; Mansur y De Angelis 2013). Si evaluamos la densidad de materiales arqueológicos en relación al área prospectada, podemos identificar dos zonas que resaltan por su mayor abundancia. La primera corresponde al Este y Sureste de la laguna Las Yeguas, donde se registraron los conjuntos con mayor cantidad de materiales (UR6, UR12, UR20) y el área de la UR17 donde se realizó la excavación. La segunda zona corresponde al Noreste de la laguna seca. En este caso los materiales correspondientes a las unidades de recolección, si bien no eran muy numerosos, los conjuntos se encontraban muy cerca uno de otro.

En líneas generales, los materiales arqueológicos superficiales son principalmente restos de talla con gran diversidad de tamaños y en los que identificamos tanto núcleos como lascas y fragmentos mayores a dos cm. También cabe destacar la recuperación de un importante número de materiales menores de dos cm, tanto en las unidades de recolección como en la excavación. Los restos líticos de este tamaño no suele ser habitual hallarlo en superficie, ya que las características de los suelos de bosque y del sedimento hacen que las piezas pequeñas se entierren con mayor facilidad que las más grandes. Es posible que este caso sea excepcional por el incendio, como discutimos más adelante.

En cuanto a los artefactos retocados, en las unidades de recolección observamos un número reducido pero diverso tipológicamente, que incluye raspadores, raederas, una preforma de proyectil y varios fragmentos de instrumento no determinados. Contrariamente, la diversidad artefactual de la excavación es baja, representada por raspadores y un fragmento de instrumento. El análisis tecnofuncional del material lítico aún está en proceso, por lo cual todavía no conocemos los usos a que fueron destinados. Sin embargo, este primer estudio nos permite ya poner en evidencia algunos criterios sobre la selección de las materias primas y sobre los distintos estadios del proceso de talla.

El análisis de las materias primas identificadas no muestra gran diversidad en su uso. El conjunto se compone fundamentalmente de riolitas de grano fino. En los afloramientos cercanos al sitio, como mencionamos anteriormente, no se pudo constatar que hubiese rastros de canteo. Sin embargo, las muestras recolectadas indican que se trata de materiales de buena calidad para la talla. Hasta el momento no podemos corroborar que el material de los afloramientos sea el mismo presente en los conjuntos, al menos hasta tanto se realicen los relevamientos en los afloramientos y otros análisis de las rocas. Por otro lado, debemos tener en cuenta que algunos de los productos de talla presentan corteza, si bien este porcentaje es bajo sugeriría que las materias primas utilizadas en esos casos pudieron ser guijarros. En otros sitios de la costa sur del lago Fagnano, hemos observado que las concentraciones de guijarros funcionaron como 
fuentes de aprovisionamiento secundario de materia prima, tal el caso del sitio Kami 1, con una abundante cantidad de materiales líticos tallados a partir de guijarros (Mansur et al. 2010; De Angelis 2015). Otro aspecto en común con el sitio Kami 1 es que las cadenas operativas representan la totalidad de la secuencia de reducción lítica. En el caso del sitio Las Yeguas no hemos registrado acumulaciones de guijarros en la laguna, ni en los cursos de agua cercanos; hasta el momento la posible fuente secundaria en este caso sería el lago Fagnano, que se encuentra a aproximadamente $1,5 \mathrm{~km}$ del sitio.

Un aspecto que nos interesa mencionar en este trabajo es el del estado de conservación de los materiales. Conociendo los datos del incendio forestal que se produjo en el lugar y de su magnitud, nuestra hipótesis de partida era que el material lítico aparecería muy alterado por la acción del fuego. Por ello, nos propusimos realizar en una primera instancia una evaluación macroscópica que a futuro, pretendemos complementar con el análisis microscópico, a fin de caracterizar los rasgos específicos de este proceso. Si bien estos estudios son iniciales, pensamos que será posible crear un modelo de interpretación de los rastros microscópicos que nos permita reconocer episodios de incendio en el registro arqueológico de zonas forestales, el que podrá ser complementado con otros análisis paleoambientales.

Desde al menos la década de 1980, existen análisis de rastros microscópicos sobre materiales termoalterados, en la mayoría de los casos procedentes del interior o la periferia de áreas de combustión (Mansur-Franchomme 1986). También existen análisis de materiales sometidos a la técnica de tratamiento térmico como preparación para la talla, un tema que está siendo estudiando actualmente, para el sur de la Argentina, por A. Frank y que ha sido abordado desde hace varias décadas por diversos equipos de la región pampeana y patagónica, que incluyen en general estudios experimentales (Cattáneo et al. 1997-98, Clemente Conte 1995, Frank 2009, 2011, 2012, 2016, Nami et al. 2000). Asimismo, se ha registrado la presencia de materiales afectados por incendios en Patagonia, principalmente en la zona cercana a la cordillera de los andes (Bellelli et al. 2003, 2008), sin embargo, no hemos encontrado trabajos en los que se realice un relevamiento y seguimiento del área post incendio como en el caso que estamos presentando.

El análisis macroscópico de los materiales del sitio revela que el aspecto más relevante es el estado de alteración térmica que presentan. Si bien en todas las unidades de recolección hay piezas con diferentes grados de alteración térmica, podemos observar algunas diferencias en cuanto a los conjuntos. En los que se ubican en las zonas Este y Sureste de la laguna, la mayor parte de las piezas están quemadas; sin embargo, también hay un número considerable de piezas en buen estado de conservación y sin rastros de termoalteración. Contrariamente, los conjuntos ubicados al Noreste de la laguna seca tienen piezas que en su mayoría están calcinadas, en menor medida quemadas y no se registraron materiales sin termoalteración. En el caso de la excavación, la cantidad de piezas sin alteración térmica es considerable, y un número muy reducido presenta rastros de quemado y calcinado (Fig. 6). En síntesis, para el material de superficie se observan diferencias en el efecto del fuego en distintos sectores del sitio, y también se observan diferencias entre el material de superficie y el registrado en la excavación. Estas características nos permiten pensar que el efecto del fuego del incendio no llega a afectar intensamente al material que se encuentra enterrado, un dato importante teniendo en cuenta que esta zona fue el foco del incendio y que paso varios días bajo los efectos del fuego. En nuestra hipótesis, podría tratarse de algo similar a lo que sucede en el caso del tratamiento térmico, donde la acción del calor es progresiva y se efectúa a través de la protección que brinda el sedimento, ya que en general el material está enterrado. El análisis tecnofuncional, que se encuentra en curso, nos permitirá corroborar estas características a escala microscópica.

Por último, es posible discutir los resultados obtenidos en este trabajo con los resultados previos del análisis de otros sitios de la costa sur del lago Fagnano. En las prospecciones realizadas hasta el momento en la región, los sitios y concentraciones de materiales se ubicaban en las cercanías inmediatas a la costa del lago. En el caso de Las Yeguas, estamos en presencia de un sitio ubicado a 1,5 $\mathrm{km}$ de la costa del lago, en un área pedemontana cercana al valle que se une con uno de los pasos cordilleranos. Se trata de un sitio extenso, al igual que los yacimientos de la localidad arqueológica Kami, pero que se diferencia en cuanto a su ubicación. Como mencionamos, la zona sur del lago en la que se encuentran sitios extensos siempre presenta gran cantidad de recursos bióticos y abióticos, en este caso concentraciones de guijarros que funcionaron como fuentes secundarias de materia prima. En el caso de Las Yeguas, es posible que su implantación se deba a la potencialidad de explotación de los recursos líticos, más que a la presencia del recurso hídrico y forestal. Para corroborarlo, nos queda pendiente la realización de otros análisis como el de procedencia materias primas del sitio y los afloramientos, como así también finalizar los análisis tecnomorfológicos y funcionales que nos permitan ampliar la información sobre el yacimiento. Por otro lado, la situación del sitio en la porción norte de la senda Beban permite asociarlo a un paso inter-montano, que pudo haber sido utilizado en el pasado, como los que hoy se conocen a partir de los datos etnográficos y los estudios actuales de sitios de altura (Mansur et al. 2020).

\section{Conclusión}

Los trabajos de campo realizados en el sitio Las Yeguas y el análisis de los materiales nos brindaron una importante cantidad y calidad de información, a pesar de ser un 
estudio inicial. El yacimiento se clasificaría dentro de los "sitios extensos" que sugieren una dinámica de ocupación del espacio que ya ha sido registrada en otros yacimientos de la costa sur del lago Fagnano. En este caso entendemos que la identificación de la abundante cantidad de materiales se debe a la gran visibilidad que produjo el incendio forestal. Pensamos que la evaluación del estado de conservación de los materiales mediante el análisis macro y microscópico nos permitirá sistematizar las características de los efectos del fuego en incendios forestales en esta área, a fin de compararlas con otros sectores de la Isla donde ya hemos identificado evidencias de incendios ocurridos hace años y en las que hemos registrado materiales arqueológicos.

El daño generado por el incendio, nos hace reflexionar sobre la importancia del cuidado del patrimonio arqueológico frente a este tipo de impactos que se suceden de manera habitual en diferentes zonas de la Isla, como consecuencia del manejo irresponsable del fuego en actividades principalmente recreativas. En el caso del sitio Las Yeguas, además de los daños y la pérdida de información que ocasionó el incendio forestal, actualmente también se observa el impacto de las tareas de reforestación. Para llevar adelante esta actividad no se ha tenido en cuenta la presencia del abundante material arqueológico, como así tampoco las características del mismo ni su ubicación a escasa profundidad de la superficie, cuando están en estratigrafía. Esta actividad no solo afecta la zona del incendio sino también la zona de extracción de los renovales, que son recogidos en otras áreas de la costa del lago.

En la actualidad los sitios arqueológicos de la faja central de la Isla Grande de Tierra del Fuego están altamente expuestos al impacto antrópico, principalmente al ocasionado por el turismo y el uso del espacio para áreas recreativas. Si bien, todavía existen zonas de la costa del lago que tienen baja circulación, en los últimos años ha aumentado la actividad turística y de senderismo de largos trayectos. Este impacto se debe principalmente a la falta de conocimiento y de políticas de gestión que promuevan el cuidado del patrimonio arqueológico. Esta situación hace necesaria la urgente puesta en valor del patrimonio arqueológico y las políticas de gestión y cuidado, que requieren una acción conjunta entre los organismos de ciencia y los entes gubernamentales que tienen injerencia en las zonas y personal que trabaja en el terreno ya sea por una actividad económica o como parte de la tarea de preservación de los ambientes, tales como Secretaría de ambiente, Áreas Protegidas provinciales, Instituto Fueguino de Turismo, entre otras. En este sentido, hemos iniciado en el año 2016 un proyecto de investigación y transferencia para comenzar a trabajar con uno de estos organismos en la puesta en valor del registro arqueológico de una de las Áreas Provinciales Protegidas de la faja central de Tierra del Fuego y que esperamos a futuro poder ampliar a otras áreas.
Los resultados obtenidos nos permiten ampliar el conocimiento sobre el uso del espacio por parte de las sociedades cazadoras recolectoras pedestres, en relación a las investigaciones que sobre la ocupación humana del área venimos llevando adelante. Esta información se suma al registro de otra cantidad de sitios relevados en la porción occidental del lago, que permiten pensar en los modos de explotación de recursos y las estrategias de ocupación del espacio, a partir de la premisa del lago como corredor que vincularía las vertientes atlántica y pacífica que pudo tener el área. Finalmente, esperamos que las características particulares del sitio ayuden a delimitar nuevas localidades arqueológicas.

Ushuaia, Tierra del Fuego, 15 de junio 2020.

\section{Agradecimientos}

A Maria Camps Graupera y Josep Maria Viladrich Jounou por su colaboración en los trabajos de campo. A la Familia Echeverria por darnos a conocer la zona de Bahía Torito. Estas investigaciones se realizan en el marco de los proyectos Análisis Tecnofuncional de Materiales Arqueológicos (ATMA), Proyecto Arqueológico Corazón de la Isla (PACI) y Proyecto de Investigación Plurianual CONICET PIP 0868.

\section{Bibliografía}

Agüero, R., Danza, R., Martinioni, D. R. y Fernández, J. (2002). Atlas Geográfico de la Provincia de Tierra del Fuego, Antártida e Islas del Atlántico Sur. Escala 1:250.000: 1-36. Ushuaia, Tierra del Fuego.

Alvarez Soncini, M. C., De Angelis, H., y Parmigiani, V. (2017). Evaluación del patrimonio arqueológico en la costa del lago Fagnano, Parque Nacional Tierra del Fuego, Argentina. Arqueología Iberoamericana, 35, 10-15. ISSN: 1989-4104.

Belardi, J. B. (2005). Paisajes arqueológicos: un estudio comparativo de diferentes ambientes patagónicos. BAR International Series 1390. Oxford, Archaeopress.

Belardi, J. B. y García, M.F. (1994). Distribuciones comparadas en Fuego-Patagonia. Actas y memorias del XI CNAA. Revista del museo de historia natural de San Rafael, XIII (1/4): 244-247.

Bellelli, C., Carballido, M., Fernández, P. y Scheinsohn, V. (2003). El pasado entre las hojas. Nueva información arqueológica del noroeste de la provincia de Chubut, Argentina. Werken, 4, 25-42.

Bellelli, C., Scheinsohn, V. y Podestá, M. M. (2008). Arqueología de pasos cordilleranos: un caso de estudio en Patagonia Norte durante el Holoceno Tardío. Boletín del museo chileno de arte precolombino, 13(2), 37-55. 
Borrero, L. A., Casiraghi, M., y Llosas, M. I. H. (1981). Arqueología del norte de Tierra del Fuego. Publicaciones del Museo Territorial, 1, 1-23.

Bridges, L. (1978 [1951]). El último confín de la Tierra. Buenos Aires, Marymar.

Cattáneo, G. R., Pupio, A., Valente M. yBarna A. (199798). Alteración térmica en dos tipos de rocas silíceas: resultados experimentales yaporte de datos para el análisis arqueológico. Relaciones de la Sociedad Argentina de Antropología XXII-XXIII, 343-361.

Chapman, A. (1986). Los Selk'nam (la vida de los Onas). Buenos Aires. Emecé.

Clemente Conte, I. (1995). Sílex y lustre térmico en el Paleolítico Medio ¿Alteración o técnica de talla? El ejemplo de Mediona 1. (Alt. Penedes Barcelona). Actas de Trabalhos de Antropología y Etnología, 35(3), 37-43.

Collado, L. (2012). Informe de evaluación del incendio forestal de Bahía Torito, enero de 2012. Dirección Provincial de Bosques del Gobierno de Tierra del Fuego, Antártida e Islas del Atlántico Sur.

Coronato, A., Seppälä, M., Ponce, J. F., y Rabassa, J. (2009). Glacial geomorphology of the Pleistocene Lake Fagnano ice lobe, Tierra del Fuego, southern South America. Geomorphology, 112, 67-81.

De Angelis, H. (2015). Arqueología de los cazadoresrecolectores de la faja central de la Isla Grande de Tierra del Fuego. Buenos Aires. Sociedad Argentina de Antropología.

De Angelis, H. y Mansur, M. E. (2015). Exploitation of allochthonous raw materials in hunter-gatherer contexts: Archaeological sites of Fagnano Lake, Tierra del Fuego, Argentina. Quaternary International, 375, 124-134.

De Angelis, H., Parmigiani, V. y Alvarez Soncini, M. C. (2013). Prospecciones en el corazón de la Isla Grande de Tierra del Fuego. En A. Zangrando, R. Barberena, A. Gil, G. Neme, M. Giardina, L. Luna y A. Tivoli (Eds.), Tendencias teórico-metodológicas y casos de estudio en la arqueología de la Patagonia, (pp. 577-586). Museo de Historia Natural de San Rafael.

De Angelis, H., Parmigiani, V., Mansur, M. E. y Piqué R. (2013). Investigaciones arqueológicas en la faja central de la Isla Grande de Tierra del Fuego, Argentina. Quaderni di Thule. Rivistaitaliana di studiamericanistici, vol. XII,297310.

Dunnell, R. y Dancey, W. (1983). The siteless survey: a regional scale data collection strategy. En M. Schiffer (Ed.), Advances in archaeological method and theory, 6 (pp. 267-287). Elsevier.

Ebert, J. (1992). Distributional archaeology. New Mexico, University of New Mexico Press.

Foley, R. (1981a). Off-site archaeology and human adaptation in eastern Africa.An analysis of regional artefact density in the Amboseli, southern Kenia. Cambridge Monographs in African Archaeology 3. BAR International Series, 97, Oxford. Archaeopress.

Foley, R. (1981b). Off-site archaeology: an alternative approach for the short sited. En I. Hodder, N. Hammond y G. Isaac (Eds.), Pattern in the past: essays in honour of David Clarke, (pp. 157-183). Cambridge University Press.

Frangi, J. L., Barrera, M. D., Puigdefábregas, J., Yapura, P. F., Arambarri, A. M., y Richter, L. L. (2004). Ecología de los bosques de Tierra del Fuego. En M. J. Arturi, J. L. Frangi y J. F. Goya (Eds.), Ecología y manejo de los bosques de Argentina, vol. 18, 88 p. Editorial de la Universidad Nacional de La Plata.

Frank, A. D. (2009). El daño térmico en artefactos líticos: estudios experimentales. Entre pasados y presentes II. Estudios contemporáneos en Ciencias Antropológicas, 35-48.

Frank, A. D. (2011). Tratamiento térmico y manejo del fuego en sociedades cazadoras-recolectoras de la Meseta Central de Santa Cruz. Tesis doctoral Inédita, Universidad Nacional de La Plata, La Plata.

Frank, A. D. (2012). Tratamiento y daño térmico de artefactos líticos en los componentes tempranos del sitio Casa del Minero 1, Santa Cruz, Argentina. Chungará, 44(1), 25-37. http://dx.doi.org/10.4067/ s0717-73562012000100003.

Frank, A. D. (2016). Tratamiento térmico de artefactos líticos en Cerro Tres Tetas 1, meseta central de Santa Cruz, Patagonia Argentina. En F. Mena (Ed.) Arqueología de la Patagonia: de Mar a Mar, (pp. 367-378).

Gusinde, M. (1982 [1937]) Los indios de Tierra del Fuego. Tomo 1: Los Selk'nam. 2 vols. Buenos Aires. Centro Argentino de Etnología Americana.

Lencinas, M. V., Martinez Pastur, G, Gallo, E. y Busso, C. (2001) Riqueza y cobertura del sotobosque en un rango de calidades de sitio en bosques de Nothofagus pumilio. Boletín de la Sociedad Argentina de botánica 36, 95.

Mansur-Franchomme, M. E. (1986). Microscopie du 
matériel lithique préhistorique: Traces d'utilisation, alterations naturelles, accidentelles et technologiques. Cahiers du Quaternaire 9. Editions du C.N.R.S, Bordeaux

Mansur, M. E. (2002). El Corazón de la Isla. Arqueología de la zona central de Tierra del Fuego. Mundos Fueguinos. Doce Miradas. Sobre Selknam, Yaganes y Kawesqar. Santiago de Chile: Taller Experimental Cuerpos Pintados 148-166.

Mansur, M. E. y De Angelis, H. (2013). Ambiente, recursos y dinámica poblacional en la faja central de Tierra del Fuego: el bosque subantártico. En A. Zangrando, R. Barberena, A. Gil, G. Neme, M. Giardina, L. Luna y A. Tivoli (Eds.) Tendencias teóricometodológicas y casos de estudio en la arqueología de la Patagonia, (pp. 587-599). Museo de Historia Natural de San Rafael.

Mansur, M. E. y De Angelis, H. (2016). Lithic resource management in mountain environments: The Andean sector of Tierra Del Fuego. Quaternary International, 402, 117-128. https://doi.org/10.1016/j. quaint.2015.10.020.

Mansur, M. E., De Angelis, H. y Parmigiani, V. (2010). Explotación de materias primas y circuitos de movilidad en la zona central de Tierra del Fuego. En R. Bárcena, H. Chiavazza (Eds.), Arqueología Argentina en el Bicentenario de la Revolución de Mayo. Actas del XVII Congreso Nacional de Arqueología Argentina, (pp. 1935-1940).

Mansur, M. E., De Angelis, H. y Parmigiani, V. (2013). Human occupations in the mountains of central Tierra del Fuego: an archaeological approach. Prehistoria Alpina, 47, 13-21.

Mansur, M. E., De Angelis, H., Parmigiani, V., Alvarez Soncini, M. C. y Franch, A. (2020). Between mountains and glacial valleys. Archaeology in the mountain ranges of the central strip of Tierra del Fuego (Argentina). Journal of the International Union of Prehistoric and Protohistoric Sciences. En prensa.

Mansur, M. E., Martinioni, D. R. y Lasa, A. (2000). La gestión de los recursos líticos en el sitio Marina 1 (Zona central de Tierra del Fuego, Argentina). En Desde el País de los Gigantes. Perspectivas arqueológicas en Patagonia. Tomo I, pp. 57-72.

Martinioni, D. R. (2010). Estratigrafía y sedimentología del Mesozoico superior-Paleógeno de la sierra de Beauvoir y adyacencias, isla Grande de Tierra del Fuego, Argentina. Tesis Doctoral Facultad de Ciencias, Universidad de Alicante.
Mataix Solera, J. (1999). Alteraciones físicas, químicas y biológicas en suelos afectados por incendios forestales: contribución a su conservación y regeneración. Tesis doctoral Inédita, Universidad Nacional de La Plata, La Plata.

Moore, D. M. (1983). Flora of Tierra del Fuego p. 396. Shrewsbury: Anthony Nelson.

Nami, H. G., Cattáneo, G. R. y Pupio M. A. (2000). Investigaciones experimentales sobre el tratamiento térmico en algunas materias primas de Pampa y Patagonia. Anales del Instituto de la Patagonia, Serie Ciencias Sociales, 28: 315-329.

Olivero, E. B., Martinioni, D.R., Malumián, N. y Palamarczuk, S. (1999). Bosquejo geológico de la Isla Grande de Tierra del Fuego, Argentina. En Actas del XIV Congreso Geológico Argentino, Actas I: 291-294.

Olivero, E. B. y Martinioni, D. R. (2001). A Review of the Geology of the Argentinian Fuegian Andes. En: Mesozoic Paleontology and Stratigraphy of South America and the South Atlantic. Journal of South American Earth Sciences, 14 (2), 175-188.

Olivero, E. B., Malumián, N. y Martinioni, D. R. (2007). Mapa Geológico de la Isla Grande de Tierra del Fuego e Isla de los Estados. Provincia de Tierra del Fuego, Antártida e Islas del Atlántico Sur. República Argentina. SEGEMAR. Escala 1:500.000. Buenos Aires.

Parmigiani V. (2014). Determination of age and sex on dental pieces of Lama guanicoe: a Methodological approach. En: Physical, chemical and biological proxies in argentine archaeology: theory, methods and applications. En D. Kligman y M. Morales (Eds.) BAR International Series 2678, pp. 63-71.

Parmigiani, V., Alvarez Soncini, M. C. y Iparraguirre, A. (2013). Localidad arqueológica Kami: sitio Kami 7, presentación general. En A. Zangrando, R. Barberena, A. Gil, G. Neme, M. Giardina, L. Luna y A. Tivoli (Eds.) Tendencias Teórico-Metodológicas y Casos de Estudio En La Arqueología de Patagonia, (pp. 601-607). Museo de Historia Natural de San Rafael.

Parmigiani, V., Alvarez Soncini, M. C. y Pichinoi, C. (2017). Primeras prospecciones arqueológicas en la costa norte del Lago Fagnano Parque Nacional Tierra del Fuego. En Libro de resúmenes de las $X$ Jornadas de Arqueología de La Patagonia, Puerto Madryn, 2017, pp. 116.

Pausas, J. 2012. Incendios Forestales. Una visión desde la ecología. Madrid. CSIC, Ed. Catarata.

Ocampo, C. y Rivas, P. (1996). Caracterización arqueológica 
preliminar del suroeste de la Tierra del Fuego. En Anales del Instituto de la Patagonia, Vol. 24, 125-151.

Orquera, L. A. y Piana, E. (1986-87). Composición tipológica y datos tecnomorfológicos y tecnofuncionales de los distintos conjuntos arqueológicos del sitio Túnel I, (Tierra del Fuego). Relaciones de la Sociedad Argentina de Antropología17 (1), 201-239.

Selzer, L. J., Oro Castro, N. P., Mansilla, P. R., Diodato, S. L., Escobar, J. M. y Moretto, A. S. (2013). Recuperación de la vegetación 1 año después de un incendio forestal en Tierra del Fuego. Boletín de la Sociedad Argentina de Botánica 1851-2372.

Thomas, D. H. (1975). Nonsite sampling in archeaeology: up the creek without a site? En J. Muller (Ed.) Sampling in archaeology pp. 61-81.

Tuhkanen, S. (1992). The Climate of Tierra del Fuego from a vegetation geographical point of view and ecoclimatic counter parts elsewhere. Acta Botnica Fennica 145, 1-64. 